University of Nebraska - Lincoln

DigitalCommons@University of Nebraska - Lincoln

Agronomy \& Horticulture -- Faculty Publications

Agronomy and Horticulture Department

2005

Effect of Control Plot Density, Control Plot Arrangement, and Assumption of Random or Fixed Effects on Nonreplicated Experiments for Germplasm Screening Using Spatial Models

\author{
Boi Sebolai \\ Botswana College of Agriculture \\ Jeffrey F. Pedersen \\ University of Nebraska-Lincoln, jpedersen1@unl.edu \\ D. B. Marx \\ University of Nebraska-Lincoln, david.marx@unl.edu \\ D. L. Boykin \\ University of Nebraska-Lincoln
}

Follow this and additional works at: https://digitalcommons.unl.edu/agronomyfacpub

Part of the Agricultural Science Commons, Agriculture Commons, Agronomy and Crop Sciences Commons, Botany Commons, Horticulture Commons, Other Plant Sciences Commons, and the Plant Biology Commons

Sebolai, Boi; Pedersen, Jeffrey F.; Marx, D. B.; and Boykin, D. L., "Effect of Control Plot Density, Control Plot Arrangement, and Assumption of Random or Fixed Effects on Nonreplicated Experiments for Germplasm Screening Using Spatial Models" (2005). Agronomy \& Horticulture -- Faculty Publications. 935. https://digitalcommons.unl.edu/agronomyfacpub/935

This Article is brought to you for free and open access by the Agronomy and Horticulture Department at DigitalCommons@University of Nebraska - Lincoln. It has been accepted for inclusion in Agronomy \& Horticulture -Faculty Publications by an authorized administrator of DigitalCommons@University of Nebraska - Lincoln. 


\title{
Effect of Control Plot Density, Control Plot Arrangement, and Assumption of Random or Fixed Effects on Nonreplicated Experiments for Germplasm Screening Using Spatial Models
}

\author{
Boi Sebolai, J. F. Pedersen,* D. B. Marx, and D. L. Boykin
}

\begin{abstract}
Early generation selection experiments typically involve several hundred to thousands of lines. Various systematic and statistical techniques have been developed to increase effectiveness and efficiencies in such experiments, including the development and application of spatial statistical models. In this study, mixed model equations were used to provide least squares means (LSMEANs) and best linear unbiased predictors (BLUPs) and compare selection effectiveness and efficiencies to observed $(Y)$ and true values in simulated experiments varying in size $(10 \times 10,20 \times 20$ and $30 \times 30$ grids $)$, control plots densities $(0,5,10,20$, and $50 \%)$, control plot arrangements (high, medium, and low A-optimality), and spatial range of influence (short and long). Results were similar for all grid sizes. In experiments in which the simulated land areas were highly variable (short range), none of the predictors, Y, LSMEAN, or BLUP, were very effective in identifying the true superior genotypes. When the simulated land areas were less variable (long range), use of BLUPs consistently resulted in the highest proportion of true top ranking genotypes identified across all control plot densities, while using the observed values consistently resulted in identification of the lowest proportion of the true top ranking genotypes. Effectiveness of LSMEANs was dependent on control plot density and arrangements. Use of BLUPs for early generation germplasm screening experiments should result in a high effectiveness in selecting truly superior germplasm and high efficiency because of the ability to account for spatial variability with the use of few or no control plots.
\end{abstract}

$I^{N}$ EARLY GENERATION selection experiments, lines numbering from several hundreds to thousands are typically evaluated. In these trials, the breeder is primarily interested in the selection and identification of superior lines for further improvement as opposed to precise estimation or prediction of their means and accurate estimation of error for comparing lines (Patterson and Silvey, 1980). In addition to the large numbers of lines that need to be evaluated, early generation trials often have a limitation in that little seed is available for each line. Thus, replication may not be always possible (Federer and Raghavarao, 1975), especially if plots are to be large enough for proper yield assessment (Kempton, 1984).

Boi Sebolai, Botswana College of Agriculture, Private Bag 0027, Gaborone Botswana; J.F. Pedersen, USDA-ARS, NPA Wheat, Sorghum and Forage Research, 344 Keim Hall, Univ. of Nebraska-Lincoln, Lincoln, NE 68583-0937; D.B. Marx, Dep. of Biometry, Univ. of Nebraska-Lincoln, Lincoln, NE 69583; D.L. Boykin, USDA, ARS, MSA, 141 Experiment Stn. Rd., Stoneville, MS 38776. Joint contribution of the USDA-ARS and the Univ. of Nebraska Agric. Exp. Stn. as Paper no. 14799, Journal Series, Nebraska Agric. Exp. Stn. Received 4 Nov. 2004. *Corresponding author (jfp@unlserve.unl.edu).

Published in Crop Sci. 45:1978-1984 (2005).

Crop Breeding, Genetics \& Cytology

doi:10.2135/cropsci2004.0643

(c) Crop Science Society of America

677 S. Segoe Rd., Madison, WI 53711 USA
Consequently, unreplicated experiments are commonplace in early generation trials (Kempton and Gleeson, 1997; Martin, 2002). Because of the number of genotypes included and large land area requirements, replicated check variety plots are usually distributed over the trial area as a method of local control, and the yields of the check variety are used as a yard-stick against which to assess the yield of each test plot (Kempton, 1984). Different systematic arrangements of check plots have been used (Kempton, 1984; Besag and Kempton, 1986; Cullis et al., 1989; Martin, 2002) to reduce the cost of including too many checks in the experiment. Baker and McKenzie (1967), however, questioned the value of systematically arranging control plots and concluded that the distribution of checks in the experiment should reflect the spatial variability pattern in the field to make adjustments on the genotype estimates.

Federer (1956, 1961, 1963), Steel (1958), and Searle (1965) introduced augmented designs to handle lack of replication of treatments. These designs were found to be of little practical value since up to $50 \%$ of the total plots were used by the check variety, and the designs emphasized testing line differences rather than estimation of gross genotypic values (Lin and Poushinsky, 1983). Various methods of adjusting the yield of each new line to the yields of nearby check plots have also been used, including nearest neighbor analysis (Papadakis, 1937; Bartlett, 1937) as well as different fertility indexes (Lin and Poushinsky, 1985; Besag and Kempton, 1986). However, these methods, though useful, do not specify the nature of the relationship between the neighboring plots.

One of the assumptions in analysis of data from designed experiments is that experimental errors are independent. In agricultural field experiments, however, adjacent plots are often correlated (Hayes, 1925; Griffee, 1928; Briggs and Shebeski, 1967; Hadjichristodoulou and Della, 1975). The presence of the correlation, if uncontrolled, may bias treatment comparisons and inflate residual variation (Grondona et al., 1996). However, best linear unbiased estimates may still be obtained if one accounts for the lack of independence (Aitken, 1934). The application of geostatistical models to account for the correlation in analysis of data from agricultural experiments is increasingly becoming important. These models use various correlation structures to model the variation related to the location of the experimental units in the field and result in an increase in the accuracy and precision of estimates of variety effects (Cullis and Gleeson 1989, 1991; Zimmerman and Harville 1991; Brownie et al., 1993; Qiao et al., 2000). Martin (1986) assumed that in spatial designs, there are positive correlations which 
decrease as the distance between plots increases and eventually become approximately zero. Matheron (1963) recognized that observations taken closer to each other tend to be more similar, and that their differences tend to have lower variances compared with those that are farther apart. As a result, comparison problems increase with separation between plots because of the increase in variability (Kempton and Gleeson, 1997). Besag and Kempton (1986) showed that spatial methods give estimators of treatment contrasts which, in the presence of appreciable spatial heterogeneity, are likely to be more efficient than traditional estimators.

Zimmerman and Harville (1991) cited an agricultural experiment as the archetypical spatial experiment where the presence of systematic heterogeneity, mainly correlation among neighboring units, is common. These patterns of variability can be described as an irregular local trend, which is neither homogeneous nor controllable by blocks and can be characterized by a linear model with spatially correlated errors. Mixed model equations developed by Henderson (1953) are a useful tool to analyze spatially correlated data (Henderson, 1975; Harville, 1976, 1977; McLean et al., 1991; Marx and Stroup, 1993). Solutions to the mixed model equations give least squares means and best linear unbiased predictors (Goldberger, 1962), known as BLUPs, (Henderson, 1973) for fixed and random effects, respectively (Henderson, 1953, Searle et al., 1992).

\section{Why Genotypes Can Be Considered Random}

Early generation trials typically involve evaluation of sizable germplasm collections or evaluation of segregating populations. In the case of the latter, the individuals under evaluation are usually random segregates of a cross or series of crosses. In the former, the germplasm lines being evaluated are often a random sample of the entire germplasm collection for the given species. The main interest in these cases is not to estimate the general mean of all the germplasm in a population but rather the relative values of the lines within a population. Hence, it can be appropriate to consider lines as random in analysis of data and rank them on BLUPs, which were originally developed for ranking and selection (Robinson, 1991). The technique is appropriate when ranking or selection involves unobservable characteristics that may be regarded as random effects.

The current practice in many germplasm evaluation trials is either to rank the observed yields of the different genotypes and identify the best performers or to consider genotypes as a fixed effect and rank them on the basis of the least squares means. The incorporation of the correlation structure among the experimental units and the ranking of genotypes on BLUPs is still an emerging science. The current availability of powerful computers capable of running hundreds of simulations of germplasm screening experiments affords the opportunity to thoroughly test the use of BLUPs for this purpose. Such simulation studies also have the inherent advantage of providing comparisons to a true genotypic value, as compared with field studies in which only comparisons among estimated values are possible. Thus the objectives of this study were to: (i) study the effect of using different densities and arrangements of control plots on the rankings of genotypes; (ii) compare the effect of ranking genotypes using observed values (Y), least squaresmeans (LSMEANs) and best linear unbiased predictors (BLUPs); (iii)

\begin{tabular}{|l|l|l|l|l|l|l|l|l|l|l|l|l|l|l|l|l|l|l|l|}
\hline & $\mathbf{x}$ & & & & & $\mathbf{x}$ & & & & & $\mathbf{x}$ & & & & & $\mathbf{x}$ & & & \\
\hline & & & $\mathbf{x}$ & & & & & $\mathbf{x}$ & & & & & $\mathbf{x}$ & & & & & $\mathbf{x}$ & \\
\hline $\mathbf{x}$ & & & & & $\mathbf{x}$ & & & & & $\mathbf{x}$ & & & & & $\mathbf{x}$ & & & & \\
\hline & & $\mathbf{x}$ & & & & & $\mathbf{x}$ & & & & & $\mathbf{x}$ & & & & & $\mathbf{x}$ & & \\
\hline & & & & $\mathbf{x}$ & & & & & $\mathbf{x}$ & & & & & $\mathbf{x}$ & & & & & $\mathbf{x}$ \\
\hline & $\mathbf{x}$ & & & & & $\mathbf{x}$ & & & & & $\mathbf{x}$ & & & & & $\mathbf{x}$ & & & \\
\hline & & $\mathbf{x}$ & & & & & $\mathbf{x}$ & & & & & $\mathbf{x}$ & & & & & $\mathbf{x}$ & \\
\hline $\mathbf{x}$ & & & & $\mathbf{x}$ & & & & & $\mathbf{x}$ & & & & & $\mathbf{x}$ & & & & \\
\hline & & $\mathbf{x}$ & & & & & $\mathbf{x}$ & & & & & $\mathbf{x}$ & & & & & $\mathbf{x}$ & & \\
\hline & & & & $\mathbf{x}$ & & & & & $\mathbf{x}$ & & & & & $\mathbf{x}$ & & & & & $\mathbf{x}$ \\
\hline & $\mathbf{x}$ & & & & & $\mathbf{x}$ & & & & & $\mathbf{x}$ & & & & & $\mathbf{x}$ & & & \\
\hline & & & $\mathbf{x}$ & & & & & $\mathbf{x}$ & & & & & $\mathbf{x}$ & & & & & $\mathbf{x}$ & \\
\hline $\mathbf{x}$ & & & & $\mathbf{x}$ & & & & & $\mathbf{x}$ & & & & & $\mathbf{x}$ & & & & \\
\hline & & $\mathbf{x}$ & & & & & $\mathbf{x}$ & & & & & $\mathbf{x}$ & & & & & $\mathbf{x}$ & & \\
\hline & & & & $\mathbf{x}$ & & & & & $\mathbf{x}$ & & & & & $\mathbf{x}$ & & & & & $\mathbf{x}$ \\
\hline & $\mathbf{x}$ & & & & & $\mathbf{x}$ & & & & & $\mathbf{x}$ & & & & & $\mathbf{x}$ & & & \\
\hline & & & $\mathbf{x}$ & & & & & $\mathbf{x}$ & & & & & $\mathbf{x}$ & & & & & $\mathbf{x}$ & \\
\hline $\mathbf{x}$ & & & & & $\mathbf{x}$ & & & & & $\mathbf{x}$ & & & & & $\mathbf{x}$ & & & & \\
\hline & & $\mathbf{x}$ & & & & & $\mathbf{x}$ & & & & & $\mathbf{x}$ & & & & & $\mathbf{x}$ & & \\
\hline & & & $\mathbf{x}$ & & & & $\mathbf{x}$ & & & & & $\mathbf{x}$ & & & & & $\mathbf{x}$ \\
\hline
\end{tabular}

Fig. 1. Check plot arrangement $A$ at a density of $20 \%$ in a $20 \times 20$ grid.

study the effect of the different sizes of experiments on the ranking of genotypes; and (iv) study the effect of the spatial range of influence on the different methods of ranking genotypes.

\section{MATERIALS AND METHODS}

Three different grid sized experiments $(10 \times 10,20 \times 20$, and $30 \times 30)$ in which there were five different control plot densities $(0,5,10,20$, and $50 \%)$ in a factorial arrangement were simulated. In grids including control plots, three patterns of control plot arrangement were included. The arrangement of control plots was based on the principle of separation so as to capture the spatial variability. The three fixed control plot arrangements were called best (A), intermediate (B), and poor (C) arrangements (Fig. 1, 2, and 3) and varied from high to

\begin{tabular}{|c|c|c|c|c|c|c|c|c|c|c|c|c|c|c|c|c|c|c|}
\hline & & & & & & & & & $\mathbf{x}$ & & & & & & & & & $\mathbf{x}$ \\
\hline \multirow{7}{*}{\multicolumn{2}{|c|}{$\mathbf{x}$}} & & & & & & $\lambda$ & & & $\mathbf{x}$ & & & & & & & $\mathbf{X}$ & \\
\hline & & & & & & 1 & & & & & $\mathbf{x}$ & & & & & $\mathbf{X}$ & & \\
\hline & & & $x$ & & $I$ & $x$ & & & & & & $\mathbf{X}$ & & & $\mathbf{x}$ & & & \\
\hline & & & & & $\mathbf{x}$ & & & & & & & & $\mathbf{x}$ & $\mathbf{x}$ & & & & \\
\hline & & & & & & & & & & & & & $\mathbf{x}$ & $\mathbf{x}$ & & & & \\
\hline & & & $x$ & & 1 & & & & & & & $\mathbf{x}$ & & & $\mathbf{x}$ & & & \\
\hline & & $x$ & & & & 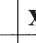 & & & & & $\mathbf{X}$ & & & & & $\mathbf{x}$ & & \\
\hline & \multirow[t]{2}{*}{$\mathbf{x}$} & & & & & & $x$ & & & $\mathbf{x}$ & & & & & & & $\mathbf{x}$ & \\
\hline $\mathbf{x}$ & & & & & & & & 1 & $\mathbf{x}$ & & & & & & & & & $\mathbf{x}$ \\
\hline & & & & & & & 1 & $\mathbf{x}$ & & & & & & & & & $\mathbf{X}$ \\
\hline & \multirow[t]{7}{*}{$\mathbf{x}$} & & & & & & $\Delta$ & & & $\mathbf{x}$ & & & & & & & $\mathbf{x}$ & \\
\hline & & $\boldsymbol{x}$ & & & & 1 & & & & & $\mathbf{x}$ & & & & & $\mathbf{x}$ & & \\
\hline & & & $x$ & & 1 & X & & & & & & $\mathbf{x}$ & & & $\mathbf{x}$ & & & \\
\hline & & & & & $\mathrm{x}$ & & & & & & & & $\mathbf{x}$ & $\mathbf{x}$ & & & & \\
\hline & & & & & I & & & & & & & & $\mathbf{x}$ & $\mathbf{x}$ & & & & \\
\hline & & & $\mathrm{K}$ & & & & & & & & & $\mathbf{x}$ & & & $\mathbf{x}$ & & & \\
\hline & & $\mathrm{x}$ & & & & 2 & & & & & $\mathbf{X}$ & & & & & $\mathbf{x}$ & & \\
\hline \multirow[b]{2}{*}{$\underline{\mathbf{x}}$} & $\mathbf{x}$ & & & & & & $x$ & & & $\mathbf{x}$ & & & & & & & $\mathbf{x}$ & \\
\hline & & & & & & & & & $\mathbf{x}$ & & & & & & & & & $x$ \\
\hline
\end{tabular}

Fig. 2. Check plot arrangement $B$ at a density of $20 \%$ in a $20 \times 20$ grid. 


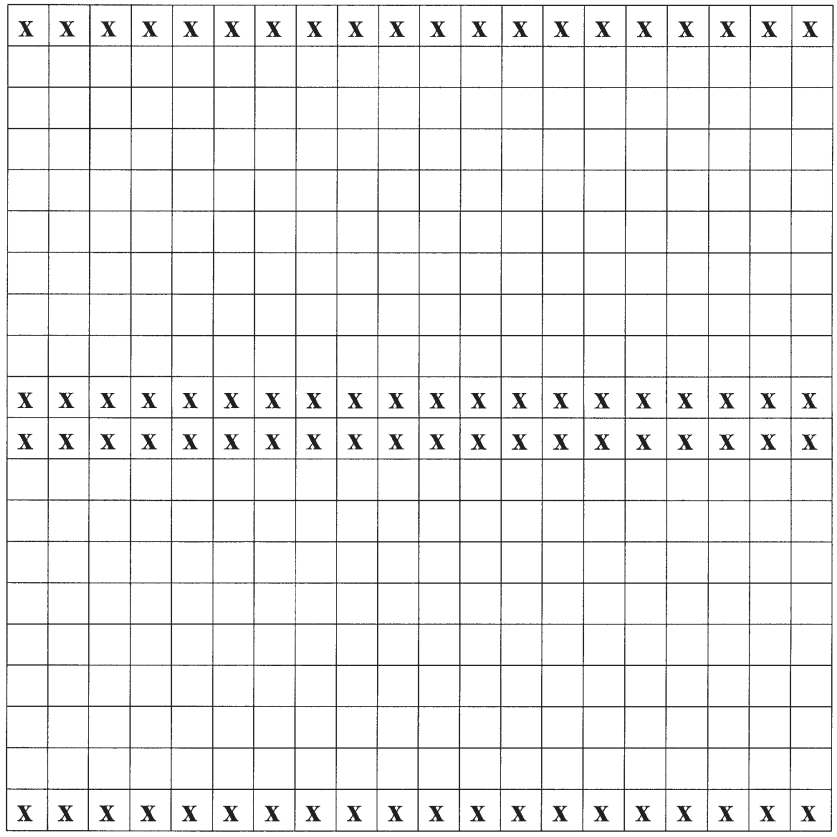

Fig. 3. Check plot arrangement $C$ at a density of $20 \%$ in a $20 \times 20$ grid.

medium to low in terms of A-optimality criterion, which is a function of the average standard error of the difference between means (averaged over all possible pairs of means). Also, two levels of the spatial range of influence, short (3.5) and long (20), were included in the experiment. Hence, there were a total of $72+6$ simulated experiments from a $4 \times 3^{2} \times 2+3 \times$ 2 factorial. In each experiment 100 data sets were simulated. In simulating data, the sill (the variance of spatially independent observations) was set at 1 , and the generated data were analyzed in two ways: genotypes treated as a random effect and genotypes treated as a fixed effect. There were three estimation methods also included in the experiment. These were BLUPs when genotypes were assumed random, least square means (LSMEANs) when genotypes were analyzed as fixed effects and observed values (Y). In simulations with $0 \%$ control plots, only BLUPs and Y were used.

\section{Data Generation}

In each grid, genotype numbers were randomly assigned to each plot. For example, in a $20 \times 20$ grid with 400 plots with a density of $20 \%$ controls, genotype numbers were assigned to each plot ranging from 1 to 321 . The control plots were assigned a treatment number of 1 with each noncontrol genotype assigned a unique positive value. The control plot placement on the grid was fixed according to the arrangement in use. The genotypes with numbers ranging from 2 to 321 were then randomly assigned to the remaining plots of the 400-plot grid or field. For simulations with $0 \%$ control plots, lines were randomly assigned on the grid.

Using PROC IML (SAS, 2000), a matrix with dimensions equivalent to the grid squared (i.e., $100 \times 100$ matrix for a $10 \times 10$ grid) was generated. Euclidean distances $(h)$ between plots in the grid were calculated. If the distance was less than the range, then $h$ was used in computing the covariance between the plots. However, if $h$ was greater than the range, then the range was not used in computing the covariance. A no nugget covariance structure with a sill set at 1 and short or long range of 3.5 and 20 , respectively, were used. The short range value allowed evaluation of the performance of each control plot density when only varieties close together were correlated. The long range allowed evaluation of performance when the spatial correlation spanned over a larger part of the grid. Using a random number generator (RANNOR) (SAS, 2000), a set of values were generated and used to compute the spatial floor to which was added a value of 10 . The random generator function in SAS returns a variate that is generated from a normal distribution with mean 0 and variance 1 . Thus, a spatial floor over the grid was generated which had a mean of 10, a sill of 1 and a range of either 3.5 or 20 . A fixed true treatment effect was generated for each genotype using the formula below:

\section{Treatment effect $=($ TRT $-(\mathrm{NTRT} / 2)) / \mathrm{NTRT}$,}

where NTRT $=$ number of genotypes in the grid excluding the control, and TRT = genotype number.

For each genotype an observed value (Y) was then computed as the sum of the treatment effect and the spatial floor:

$$
Y=\text { treatment effect }+ \text { spatial floor. }
$$

The spatial floor was simulated to have a spherical covariance structure with either of the two ranges.

\section{Data Analysis}

The first step of the analysis involved the estimation the spatial structure of the simulated data using control plots only. This was done to estimate the parameters of the covariance function. These parameter estimates were then used in analyzing the whole data set using Proc Mixed (SAS, 2000).

In each iteration, a convergence code was set. A code of 1 was assigned if the analysis converged to reasonable estimates. If the analysis converged but the parameters were not reasonable, a code of 2 was assigned, and a code of 3 was assigned where the analysis failed to converge. The covariance parameter estimates were output to a data file for use in the next step of the analysis.

For the analyses with a convergence code of 1 , a spherical spatial structure was used to analyze the full data set including control and experimental genotypes.

The full data set was analyzed once with genotypes considered as a random factor and once as a fixed factor. In cases where the analyses were coded 2 or 3 , a different spatial structure, the linear structure, with no nugget effect was used instead of the spherical. This covariance structure was chosen since its choice of parameters does not affect the estimates, i.e., LSMEANs and their ranks (Marx and Thompson, 1985).

For each grid size, $10 \times 10,20 \times 20$, and $30 \times 30$, data sets across treatment combinations, Y, BLUPs, and LSMEANs were merged. Pearson correlations of the true genotype effect with Y, BLUPs and LSMEANs were determined. A similar process was followed for simulations with $0 \%$ control plots where BLUPs and Y were correlated to the true genotype effect. In each experiment, genotypes were ranked on the basis of Y, LSMEANs, and BLUPs to obtain the predicted top ranking $20 \%$ of the genotypes. From the top ranked predicted $20 \%$ of the genotypes, the proportion of true top ranking genotypes identified by Y, LSMEANs, and BLUPs was determined.

When analyzing the correlation coefficients and proportions, the analysis was performed separately for each experiment $(10 \times 10,20 \times 20$, and $30 \times 30)$. The experimental design used in the analysis was a repeated measure in a completely randomized design with one hundred iterations (I). The main plot treatment was as a factorial arrangement of arrangement $(\mathrm{A})$, density $(\mathrm{P})$ and range $(R)$, and the repeated measure factor was the methods of ranking (M). 
Table 1. Analyses of variance for Pearson correlations and covariance parameter estimates for $20 \times 20$ grid.

\begin{tabular}{|c|c|c|c|c|}
\hline Cov Parm & Estimate & Standard error & $Z$ value & $\operatorname{Pr} Z$ \\
\hline ITER(ARRANGEMENT*DENSITY*RANGE) & 0.001058 & 0.000049 & 21.46 & $<0.0001$ \\
\hline Residual & 0.001584 & 0.000035 & 45.34 & $<0.0001$ \\
\hline Effect & Num DF & Den DF & $F$ value & $\operatorname{Pr}>\boldsymbol{F}$ \\
\hline ARRANGEMENT & 2 & 2360 & $\mathbf{5 3 . 9 0}$ & $<0.0001$ \\
\hline DENSITY & 3 & 2360 & 223.37 & $<\mathbf{0 . 0 0 0 1}$ \\
\hline ARRANGEMENT*DENSITY & 6 & 2360 & 1.84 & 0.0877 \\
\hline RANGE & 1 & 2360 & 17378.2 & $<0.0001$ \\
\hline ARRANGEMENT*RANGE & 2 & 2360 & $\mathbf{7 . 0 6}$ & 0.0009 \\
\hline DENSITY*RANGE & 3 & 2360 & 2.14 & 0.0928 \\
\hline ARRANGEMENT*DENSITY*RANGE & 6 & 2360 & 1.55 & 0.1589 \\
\hline METHOD & 2 & 4027 & 22916.1 & $<0.0001$ \\
\hline ARRANGEMENT*METHOD & 4 & 4027 & 128.32 & $<0.0001$ \\
\hline DENSITY*METHOD & 6 & 4027 & 360.91 & $<0.0001$ \\
\hline ARRANGEMENT*DENSITY*METHOD & 12 & 4027 & 14.34 & $<0.0001$ \\
\hline RANGE*METHOD & 2 & 4027 & 5054.99 & $<0.0001$ \\
\hline ARRANGEMENT*RANGE*METHOD & 4 & 4027 & 19.26 & $<\mathbf{0 . 0 0 0 1}$ \\
\hline DENSITY*RANGE*METHOD & 6 & 4027 & 4.92 & $<0.0001$ \\
\hline ARRANGEMENT*DENSITY*RANGE*METHOD & 11 & 4027 & $\mathbf{7 . 7 4}$ & $<0.0001$ \\
\hline
\end{tabular}

\section{RESULTS}

Results were very similar for all grid sizes, so only the results from the $20 \times 20$ experiments are reported. There was a significant four-factor interaction between control plot arrangements, control plot densities, range, and methods of ranking genotypes (Table 1). The major effects, as indicated by the size of their $F$ statistic, were due to the range, method of ranking genotype, and the range by method interaction. Secondary effects were due to density of control plots, two factor interactions of density by method, as well as a control plot arrangement by method interaction.

\section{Correlations with True Treatment Effects}

For all control plot arrangements, A, B, and C, and a range of 3.5, the average Pearson correlation of the $\mathrm{Y}$ with the true genotype effects remained approximately constant at $r=0.27$ to $r=0.30$ across all control plot densities, zero to $50 \%$ (Table 2). Increasing the range to 20 resulted in an increase in the correlations to $r=$ 0.35 to $r=0.37$ which remained approximately constant from the zero to $50 \%$ control plot density in all control plot arrangements (Table 3). Correlations of the BLUPs with true genotype effects also remained relatively constant across all control plot densities and arrangements with $r=0.43$ to $r=0.45$ when using a range of 3.5 and $r=0.72$ to $r=0.76$ when using a range of 20 (Tables 2 and 3). Thus, control plot density did not appreciably affect BLUPs.

Unlike BLUPs and Y, the correlations of LSMEANs with the true genotype effects changed with the control plot density and did so at both ranges. For all control plot arrangements and grid sizes, the Pearson correlation coefficients for the true genotype effect and LSMEANs increased with increasing control plot density (Tables 2 and 3). The amount of increase depended on the range and control plot arrangement. For control plot arrangement $\mathrm{A}$, the correlation increased until at $50 \%$ control plot density, where the correlation of LSMEANs with treatment effect was equivalent to that obtained with BLUPs. For control plot arrangements B and C, the increase was reduced. Using a range of 3.5, the correlation coefficients at the $5 \%$ control plot density were about equal to the correlation coefficients of the true treatment effect and $\mathrm{Y}$ and increased to slightly less than the correlation coefficients for the true treatment effect and BLUPs at 50\% control plot density. Using a

Table 2. Mean Pearson correlations and standard errors for true genotype value with BLUPs, LSMEANs, and observed values, in simulated germplasm screening experiments with a range of 3.5 and a $20 \times 20$ grid.

\begin{tabular}{|c|c|c|c|c|}
\hline \multicolumn{2}{|c|}{ Control plot } & \multirow[b]{2}{*}{ BLUP } & \multirow[b]{2}{*}{ LSMEAN } & \multirow[b]{2}{*}{ Observed value } \\
\hline Arrangement & Density & & & \\
\hline \multirow[t]{5}{*}{$\mathbf{A}$} & $\mathbf{0}$ & $0.432 \pm 0.005$ & (not estimable) & $0.282 \pm 0.004$ \\
\hline & 5 & $\mathbf{0 . 4 3 3} \pm \mathbf{0 . 0 0 5} \dagger$ & (did not converge) & $0.281 \pm 0.005$ \\
\hline & 10 & $0.437 \pm 0.005$ & $0.312 \pm 0.006$ & $0.280 \pm 0.006$ \\
\hline & 20 & $0.429 \pm 0.005$ & $0.358 \pm 0.005$ & $0.273 \pm 0.005$ \\
\hline & 50 & $0.450 \pm 0.006$ & $0.446 \pm 0.005$ & $0.296 \pm 0.005$ \\
\hline \multirow[t]{5}{*}{ B } & $\mathbf{0}$ & $0.432 \pm 0.005$ & (not estimable) & $0.282 \pm 0.004$ \\
\hline & 5 & $0.432 \pm 0.005$ & $0.283 \pm 0.005$ & $0.280 \pm 0.005$ \\
\hline & 10 & $\mathbf{0 . 4 3 5} \pm 0.005$ & $0.315 \pm 0.005$ & $0.284 \pm 0.005$ \\
\hline & 20 & $0.436 \pm 0.006$ & $0.320 \pm 0.005$ & $0.281 \pm 0.005$ \\
\hline & 50 & $0.447 \pm 0.008$ & $0.411 \pm 0.005$ & $0.280 \pm 0.005$ \\
\hline \multirow[t]{5}{*}{$\mathbf{C}$} & 0 & $0.432 \pm 0.005$ & (not estimable) & $0.282 \pm 0.004$ \\
\hline & 5 & $0.431 \pm 0.005$ & $0.272 \pm 0.005$ & $0.271 \pm 0.005$ \\
\hline & 10 & $\mathbf{0 . 4 3 5} \pm \mathbf{0 . 0 0 5}$ & $0.295 \pm 0.005$ & $0.277 \pm 0.005$ \\
\hline & 20 & $0.440 \pm 0.006$ & $0.296 \pm \mathbf{0 . 0 0 5}$ & $0.282 \pm 0.005$ \\
\hline & 50 & $\mathbf{0 . 4 5 0} \pm \mathbf{0 . 0 0 7}$ & $0.378 \pm 0.005$ & $0.285 \pm 0.005$ \\
\hline
\end{tabular}

† The Pearson correlations used in the LSMEANs analyses were computed on the converged LSMEANs resulting in variable sample size. Standard errors are therefore presented instead of LSDs. 
Table 3. Mean Pearson correlations and standard errors for true genotype value with BLUPs, LSMEANs, and observed values, in simulated germplasm screening experiments with a range of 20 and a $20 \times 20$ grid.

\begin{tabular}{|c|c|c|c|c|}
\hline \multicolumn{2}{|c|}{ Control Plot } & \multirow[b]{2}{*}{ BLUP } & \multirow[b]{2}{*}{ LSMEAN } & \multirow[b]{2}{*}{ Observed value } \\
\hline Arrangement & Density & & & \\
\hline \multirow[t]{5}{*}{$\mathbf{A}$} & 0 & $0.722 \pm 0.002$ & (not estimable) & $0.365 \pm 0.008$ \\
\hline & 5 & $0.724 \pm 0.005$ & $0.570 \pm 0.006$ & $0.361 \pm 0.006$ \\
\hline & 10 & $0.729 \pm 0.005$ & $0.643 \pm 0.006$ & $0.368 \pm 0.006$ \\
\hline & 20 & $0.732 \pm 0.005$ & $0.693 \pm 0.005$ & $0.345 \pm 0.005$ \\
\hline & 50 & $0.757 \pm 0.005$ & $0.759 \pm 0.005$ & $0.363 \pm 0.005$ \\
\hline \multirow[t]{5}{*}{ B } & 0 & $\mathbf{0 . 7 2 2} \pm \mathbf{0 . 0 0 2}$ & (not estimable) & $\mathbf{0 . 3 6 5} \pm \mathbf{0 . 0 0 8}$ \\
\hline & 5 & $\mathbf{0 . 7 2 3} \pm \mathbf{0 . 0 0 5}$ & $0.558 \pm 0.006$ & $\mathbf{0 . 3 5 8} \pm \mathbf{0 . 0 0 6}$ \\
\hline & 10 & $\mathbf{0 . 7 3 3} \pm \mathbf{0 . 0 0 5}$ & $0.618 \pm 0.006$ & $0.352 \pm 0.006$ \\
\hline & 20 & $0.726 \pm 0.005$ & $0.628 \pm 0.005$ & $0.369 \pm 0.005$ \\
\hline & 50 & $0.741 \pm 0.005$ & $0.726 \pm 0.005$ & $0.367 \pm 0.005$ \\
\hline \multirow[t]{5}{*}{ C } & 0 & $0.722 \pm 0.002$ & (not estimable) & $0.365 \pm 0.008$ \\
\hline & 5 & $0.726 \pm 0.005$ & $\mathbf{0 . 5 3 8} \pm 0.006$ & $0.351 \pm 0.006$ \\
\hline & 10 & $0.731 \pm 0.005$ & $0.539 \pm 0.005$ & $0.360 \pm 0.005$ \\
\hline & 20 & $0.732 \pm 0.005$ & $0.554 \pm 0.005$ & $0.368 \pm 0.005$ \\
\hline & 50 & $0.736 \pm 0.005$ & $0.700 \pm 0.005$ & $0.366 \pm 0.005$ \\
\hline
\end{tabular}

range of 20, correlation coefficients of LSMEANs and true treatment effects were approximately double the correlation of $\mathrm{Y}$ and the true treatment effects at $5 \%$ control plot density, and they increased to the correlation of BLUPs with the true treatment effect at the $20 \%$ control plot density in arrangement A. In control plot arrangement $\mathrm{C}$ there was little change in the correlation of LSMEANs with true treatment effects from 5 to $20 \%$ control plot density, but the correlation approached that of the BLUPs with true treatment effects at $50 \%$ control plot density.

In general, the results showed the strongest and constant correlation of true treatment effects with BLUPs and increasing correlations of LSMEANs and true treatment effects with increasing control plot density, while the correlation was weak with observed values at all control plot densities, control plot arrangements, and ranges.

\section{Proportion of Selected Genotypes in the True Top $20 \%$}

Analysis of variance results for factors affecting the proportion of true top ranking genotypes in the true top $20 \%$ are presented in Table 4 . These results were similar
Table 5. Mean proportions identified in the true top $20 \%$ of genotypes and LSDs using BLUPs, LSMEANs, and observed values, in simulated germplasm screening experiments with a range of 3.5 and a $20 \times 20$ grid.

\begin{tabular}{|c|c|c|c|c|}
\hline \multicolumn{2}{|c|}{ Control plot } & \multirow[b]{2}{*}{ BLUP } & \multirow[b]{2}{*}{ LSMEAN } & \multirow[b]{2}{*}{ Observed value } \\
\hline Arrangement & Density & & & \\
\hline \multirow[t]{5}{*}{$\mathbf{A}$} & 0 & 0.388 & (not estimable) & 0.316 \\
\hline & $\mathbf{5}$ & 0.395 & 0.316 & 0.315 \\
\hline & 10 & 0.393 & 0.336 & 0.321 \\
\hline & 20 & 0.395 & 0.358 & 0.316 \\
\hline & 50 & 0.414 & 0.414 & 0.328 \\
\hline \multicolumn{5}{|c|}{ LSD within row $=0.012$ LSD between rows $=0.015$} \\
\hline \multirow[t]{5}{*}{ B } & 0 & 0.388 & (not estimable) & 0.316 \\
\hline & $\mathbf{5}$ & 0.385 & 0.321 & 0.316 \\
\hline & 10 & 0.392 & 0.332 & 0.315 \\
\hline & 20 & 0.384 & 0.332 & 0.310 \\
\hline & $\mathbf{5 0}$ & 0.395 & 0.385 & 0.315 \\
\hline \multicolumn{5}{|c|}{ LSD within row $=0.012$ LSD between rows $=-0.015$} \\
\hline C & 0 & 0.388 & (not estimable) & 0.316 \\
\hline & $\mathbf{5}$ & 0.383 & 0.311 & 0.309 \\
\hline & 10 & 0.393 & 0.329 & 0.312 \\
\hline & 20 & 0.389 & 0.322 & 0.316 \\
\hline & 50 & 0.381 & 0.356 & $\mathbf{0 . 3 2 2}$ \\
\hline \multicolumn{5}{|c|}{ 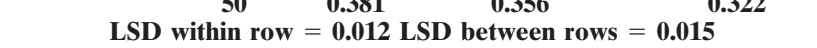 } \\
\hline
\end{tabular}

in all grids, hence only $20 \times 20$ results are reported. There was a significant four-factor interaction between all the four factors simulated: control plot density, control plot arrangement, range and method. These results were also similar for all grids sizes. On the basis of sizes of the $F$ statistic, major effects were due to range, method, and range by method interaction while control plot density, control plot arrangement, and density by method interaction were secondary effects.

When ranking genotypes on observed values $(\mathrm{Y})$, the proportion of true top ranking genotypes identified remained approximately constant at 0.31 to 0.33 in simulations with a range of 3.5 , and 0.35 to 0.37 in simulations with a range of 20 at all control plot densities and control plot arrangements (Tables 5 and 6). Similarly, when using BLUPs, the proportion of true top ranking genotypes identified remained approximately constant at 0.38 to 0.41 in simulations with a range of 3.5 , and 0.56 to 0.60 in simulations with a range of 20 for all control plot densities and control plot arrangements.

Table 4. Analysis of variance for proportion for the true top $20 \%$ of genotypes identified and covariance parameter estimates for $20 \times$ 20 grid.

\begin{tabular}{|c|c|c|c|c|}
\hline Cov Parm & Estimate & Standard error & $Z$ value & $\operatorname{Pr} Z$ \\
\hline $\begin{array}{l}\text { ITER(ARRANGEMENT*DENSITY*RANGE) } \\
\text { Residual }\end{array}$ & $\begin{array}{l}0.001196 \\
0.001840\end{array}$ & $\begin{array}{l}0.000054 \\
0.000038\end{array}$ & $\begin{array}{r}22.16 \\
8.74\end{array}$ & $\begin{array}{l}<0.0001 \\
<0.0001\end{array}$ \\
\hline Effect & Num DF & Den DF & $F$ value & $\operatorname{Pr}>\boldsymbol{F}$ \\
\hline ARRANGEMENT & 2 & 2376 & 32.58 & $<0.0001$ \\
\hline DENSITY & 3 & 2376 & $\mathbf{7 7 . 7 2}$ & $<0.0001$ \\
\hline ARRANGEMENT*DENSITY & 6 & 2376 & 3.14 & 0.0046 \\
\hline RANGE & 1 & 2376 & 5579.58 & $<0.0001$ \\
\hline ARRANGEMENT*RANGE & 2 & 2376 & 2.78 & 0.0622 \\
\hline DENSITY*RANGE & 3 & 2376 & 3.40 & 0.0171 \\
\hline ARRANGEMENT*DENSITY*RANGE & 6 & 2376 & 1.24 & 0.2829 \\
\hline METHOD & 2 & 4752 & 7067.68 & $<0.0001$ \\
\hline ARRANGEMENT*METHOD & 4 & 4752 & 44.68 & $<0.0001$ \\
\hline DENSITY*METHOD & 6 & 4752 & 130.36 & $<0.0001$ \\
\hline ARRANGEMENT*DENSITY*METHOD & 12 & 4752 & 5.20 & $<0.0001$ \\
\hline RANGE*METHOD & 2 & 4752 & 1929.59 & $<0.0001$ \\
\hline ARRANGEMENT*RANGE*METHOD & 4 & 4752 & 9.84 & $<\mathbf{0 . 0 0 0 1}$ \\
\hline DENSITY*RANGE*METHOD & 6 & 4752 & 8.75 & $<0.0001$ \\
\hline ARRANGEMENT*DENSITY*RANGE*METHOD & 12 & 4752 & 2.02 & 0.0189 \\
\hline
\end{tabular}


Table 6. Mean proportions identified in the true top $20 \%$ of genotypes and LSDs using BLUPs, LSMEANs, and observed values, in simulated germplasm screening experiments with a range of 20 and a $20 \times 20$ grid.

\begin{tabular}{|c|c|c|c|c|}
\hline \multicolumn{2}{|c|}{ Control plot } & \multirow[b]{2}{*}{ BLUP } & \multirow[b]{2}{*}{ LSMEAN } & \multirow[b]{2}{*}{ Observed value } \\
\hline Arrangement & Density & & & \\
\hline \multirow[t]{5}{*}{$\mathbf{A}$} & $\mathbf{0}$ & 0.556 & (not estimable) & 0.358 \\
\hline & 5 & 0.568 & 0.470 & 0.356 \\
\hline & 10 & 0.573 & 0.511 & 0.353 \\
\hline & 20 & 0.573 & 0.543 & 0.356 \\
\hline & 50 & 0.595 & 0.598 & 0.358 \\
\hline \multicolumn{5}{|c|}{ LSD within row $=0.012$ LSD between rows $=0.015$} \\
\hline \multirow[t]{5}{*}{ B } & $\mathbf{0}$ & 0.556 & (not estimable) & 0.358 \\
\hline & 5 & 0.566 & 0.461 & 0.355 \\
\hline & 10 & 0.581 & 0.508 & 0.356 \\
\hline & 20 & 0.577 & 0.507 & 0.365 \\
\hline & 50 & 0.582 & 0.576 & 0.368 \\
\hline \multicolumn{5}{|c|}{ LSD within row $=0.012$ LSD between rows $=-0.015$} \\
\hline $\mathbf{C}$ & 0 & 0.556 & (not estimable) & 0.358 \\
\hline & 5 & 0.570 & 0.448 & 0.358 \\
\hline & 10 & 0.571 & 0.464 & 0.355 \\
\hline & 20 & 0.570 & 0.455 & 0.359 \\
\hline & 50 & 0.574 & 0.543 & 0.354 \\
\hline
\end{tabular}

When LSMEANs and a range of 3.5 are used, the proportion of true top ranking genotypes identified increased with increasing control plot density up to 0.41 , 0.39 , and 0.36 in arrangements $\mathrm{A}, \mathrm{B}$, and C, respectively. At a range of 20 , however, the proportion of true top ranking genotypes identified increased up to $0.60,0.58$, and 0.54 for arrangements A, B, and C, respectively. The proportions of true top ranking genotypes identified by LSMEANs and BLUPs were equivalent when using a range of 20 for control plot arrangements $\mathrm{A}$ and $\mathrm{B}$ at a control plot density of $50 \%$.

\section{DISCUSSION}

Using observed values to rank or select genotypes ignores the existence of the spatial correlations, while using either BLUPs or LSMEANs means accounts for this additional information about the field. As expected, our findings indicate that ranking of genotypes can be improved by accounting for spatial variation. That both BLUPs and LSMEANs were more effective for selecting superior genotypes than the use of observed values confirms the findings of Besag and Kempton (1986) that an analysis where spatial information is accounted for produces more accurate estimates.

The effectiveness of LSMEANs for selecting superior genotypes generally increased as control plot density was increased, but such increases in effectiveness are associated with a decrease in efficiency due to the increase in proportion of control plots (up to $50 \%$ ). The increasing effectiveness in identifying true superior genotype with an increasing density of control plots implies that more control plots in the field provide more spatial information. These results support Briggs and Shebeski's (1967) findings that the small number of control plots used in early generation trials could be one of the limiting factors for efficiency of selection only when genotypes are considered a fixed effect. Thus, using control plots to improve the estimates of the value of new genotypes (Wianco, 1914) is important only if genotypes are considered a fixed effect, and control plots are of questionable value (Baker and McKenzie, 1967) if genotypes are considered a random effect.

In all grids, ranges, and arrangements of control plots, BLUPs were more highly correlated to the true genotype effects than simulated observed values and the LSMEANs at low and intermediate control plot densities. Both the BLUP correlation coefficients and proportions identified in the true top $20 \%$ were little affected by control plot density and arrangement of control plots even at the lowest density, $0 \%$. This implies that control plots are contributing very little, if any, to the estimation of the BLUPs. Previous authors indicate that the estimation procedure of the BLUPs accounts for the covariance structure in the field (Stein, 1956; James and Stein, 1961; Hoerl, 1962; Hoerl and Kennard, 1970a, 1970b). Thus, the BLUPs were able to identify superior genotypes more effectively and efficiently than other methods irrespective of the control plot density because the method took advantage of the random spherical covariance structure in our simulated fields, confirming Aitken's (1934) findings. Therefore, considering genotypes to be a random effect is similar to accounting for or including the correlation between independent variables in estimating parameters as it is done in ridge regression.

\section{CONCLUSIONS}

In experiments in which the simulated land areas were highly variable (short range), none of the predictors $\mathrm{Y}$, LSMEAN, or BLUP were very effective in identifying the true superior genotypes. However, when the simulated land areas were less variable (long range), the use of BLUPs with few or no control plots and LSMEANs with optimal control plot arrangement and high density were both much more effective in identifying the true superior genotypes than the use of observed values. Thus, it is concluded for early generation screening that it is critical to first control spatial variability (i.e., create or select a uniform research field) and then incorporate the spatial information in the analysis.

Of the three methods used to estimate genotype value, BLUPs consistently resulted in the highest proportion of true top ranking genotypes identified across all control plot densities, even at the $0 \%$ control plot density, while using the observed values consistently resulted in identification of the lowest proportion of the true top ranking genotypes. This trend was similar across grids, arrangements, and ranges in these simulation studies. Effectiveness of LSMEANs was dependent on control plot density and arrangement. Use of BLUPs for early generation germplasm screening experiments should result in high effectiveness in selecting truly superior germplasm and high efficiency because of the ability to account for spatial variability with the use of few or no control plots. 


\section{REFERENCES}

Aitken, A.C. 1934. On least squares and linear combinations of observations. Proc. Roy. Soc. Edinburgh 55:42-48.

Baker, R.J., and R.I.H. McKenzie. 1967. Use of control plots in yield trials. Crop Sci. 7:335-337.

Bartlett, M.S. 1937. Some examples of statistical methods of research in agriculture and applied biology (with discussion). J. Roy. Statist. Soc. Supp. 4:137-183.

Besag, J., and R.A. Kempton. 1986. Statistical analysis of field experiments using neighbouring plots. Biometrics 42:231-251.

Briggs, K.G., and L.H. Shebeski. 1967. Implications concerning the frequency of control plots in wheat breeding nursieries. Can. J. Plant Sci. 48:149-153.

Brownie, C., D.T. Bowman, and J.W. Burton. 1993. Estimating spatial variation of data from yield trials: A comparison of methods. Agron. J. 85:1244-1253.

Cullis, B.R., and A.C. Gleeson. 1989. Efficiency of neighbour analysis for replicated field trials in Australia. J. Agric. Sci. (Cambridge) 113:233-239

Cullis, B.R., and A.C. Gleeson. 1991. Spatial analysis of field experiments-An extension to two dimensions. Biometrics 47:1449-1460.

Cullis, B.R., L.J. Warwick, J.A. Fisher, B.J. Read, and A.C. Gleeson. 1989. A new procedure for the analysis of early generation variety trials. Appl. Statist. 38:361-375.

Federer, W.T. 1956. Augmented (or Hoonuiaku) designs. Hawaiian Planter's Rec. 55:191-208.

Federer, W.T. 1961. Augmented designs with one-way elimination of heterogeneity. Biometrics 17:447-473.

Federer, W.T. 1963. Procedures and designs useful for screening material in selection and allocation, with a bibliography. Biometrics 19:553-587.

Federer, W.T., and D. Raghavarao. 1975. On augmented designs. Biometrics 31:29-35.

Goldberger, B.J. 1962. Best linear unbiased prediction in general linear regression model. J. Am. Statist. Assoc. 57:369-375.

Griffee, F. 1928. Correcting yields in rodrow trials with the aid of regression equation. J. Am. Soc. Agron. 20:569-581.

Grondona, M.O., J. Crossa, P.N. Fox, and W.H. Pfeiffer. 1996. Analysis of variety yield trials using two-dimensional separable ARIMA process. Biometrics. 52:763-770.

Hadjichristodoulou, A., and A. Della. 1975. Frequency of control plots in screening nurseries for protein content. Euphytica 25:387-391.

Harville, D.A. 1976. Extension of the Gauss-Markov theorem to include the estimation of random effects. Ann. Statist. 4:384-395.

Harville, D.A. 1977. Maximum likelihood approaches to variance component estimation and to related problems. J. Am. Statist. Assoc. 72:320-338.

Hayes, H.K. 1925. Control of soil heterogeneity and use of the probable error concept in platn breeding studies. Minn. Res. Bull. 30:1-21.

Henderson, C.R. 1953. Estimation of variance and covariance components. Biometrics 9:226-252.

Henderson, C.R. 1973. Sire evaluation and genetic trends. p. 10-41. In Proceedings of the Animal Breeding and Genetics Symposium in Honour of Dr. Jay L. Lush. Am. Co. Anim. Sci., Am. Dairy Sci. Assoc., and Poultry Sci. Assn., Champaign IL.

Henderson, C.R. 1975. Best linear unbiased estimation and prediction under a selection model. Biometrics 31:423-447.
Hoerl, A.E. 1962. Application of ridge analysis to regression problems. Chem. Engineer. Prog. 58:54-59.

Hoerl, A.E., and R.W. Kennard. 1970a. Ridge regression: Biased estimation for nonorthogonal problems. Technometrics 12:55-67.

Hoerl, A.E., and R.W. Kennard. 1970b. Ridge regression: Applications to nonorthogonal problems. Technometrics 12:69-82.

James, W., and C. Stein. 1961. Estimation with quadratic loss. Proc. of the fourth Berkeley Symposium, University of California Press. 1:361-379.

Kempton, R.A. 1984. The design and analysis of unreplicated field trials. Votr. Pflanzenzuchtg. 7:219-242.

Kempton, R.A., and A.C. Gleeson. 1997. Unreplicated trials. In R.A. Kempton and P.N. Fox (ed.) Statistical methods for plant variety evaluation. Chapman and Hall Publishers.

Lin, C.S., and G. Poushinsky. 1983. A modified augmented design for an early stage of plant selection involving a large number of test lines without replication. Biometrics 39:553-561.

Lin, C.S., and G. Poushinsky. 1985. A modified augmented design (type 2) for rectangular blocks. Can. J. Plant Sci. 65:743-749.

Martin, R.J. 1986. On the design of experiments under spatial correlation. Biometrika 73:247-277.

Martin, R.J. 2002. Comparing and contrasting some environmental and experimental design problems. Environmetrics 12:273-287.

Matheron, G. 1963. Principles of geostatistics. Econ. Geol. 58:1246-1266.

Marx, D.B., and W.W. Stroup. 1993. Analysis of spatial variability using PROC MIXED. In Proceedings of the 1993 Kansas State University Conference on Applied Statistics in Agriculture. Kansas State University, Manhattan, KS.

Marx, D.B., and K.C. Thompson. 1985. Practical aspects of agricultural kriging. Bulletin 903, Arkansas Agricultural Experiment Station, University of Arkansas, Fayetteville, AR.

McLean, R.A., W.L. Saunders, and W.W. Stroup. 1991. A unified approach to mixed linear models. Am. Statist. 45:54-64.

Papadakis, J. 1937. Methode statistique por des experiences de champs'. Inst. Amel. Plantes, Salonique, (Greece). Bull Sci. 23.

Patterson, H.D., and V. Silvey. 1980. Statutory and recommended list trials of crop varieties in the United Kingdom. J. Roy. Statist. Soc. Ser. A (General) 143:219-252.

Qiao, C.G., K.E. Basford, I.H. DeLacy, and M. Cooper. 2000. Evaluation of experimental designs and spatial analyses in wheat breeding trials. Theor. Appl. Genet. 100-9-16.

Robinson, G.K. 1991. That BLUP is a good thing: The estimation of random effects. Statist. Sci. 6:15-51.

SAS Institute. 2000. Online Doc. Version 8. SAS Institute, Inc., Cary, NC.

Searle, S.R. 1965. Computing formulae for analyzing augmented random complete block design. BU-207-M in the Biometrics Unit Mimeo Series, Cornell University, Ithaca, NY.

Searle, S.R., G. Casella, and C.E. McCulloch. 1992. Variance components. John Wiley \& Sons

Steel, R.G.D. 1958. A class of augmented designs. Math. Res. Center Tech. Summary Report No. 56, University of Wisconsin.

Stein, C. 1956. Inadmissibility of the usual estimator for the mean of a multivariate normal distribution. Proc. Third Berkeley Symp. Math. Ststist. Probab. 1:197-206 Univ. California Press, Berkeley.

Wianco, A.T. 1914. Use and management of check plots in soil fertility investigations. J. Am. Soc. Agron. 6:122-124.

Zimmerman, D.L., and D.A. Harville. 1991. A random field approach to the analysis of field-plot experiments and other spatial experiments. Biometrics 47:223-239. 